\title{
Farklı endodontik irrigasyon aktivasyon teknikleri kullanılarak yapay oluklardan debriz uzaklaştırılması: ex vivo
}

\author{
Mügem Aslı Ekici,* Bağdagül Helvacıoğlu Kıvanç, \\ Adil Ekici, Özgür Uzun \\ Endodonti Anabilim Dalı, Diş Hekimliği Fakültesi, Gazi \\ Üniversitesi, Ankara, Türkiye
}

\section{ÖZET}

AmAÇ: Bu çalışmanın amacı, farklı irrigasyon aktivasyon tekniklerinin kök kanallarında oluşturulan yapay oluklardan debriz uzaklaştırma etkinliklerinin karşılaştırılmasıdır.

GeREÇ VE YönTEM: Yirmi adet üst keser dişin kronları uzaklaştırıldıktan sonra kök kanal preparasyonunu yapıldı. Örnekler, akrilik rezin kullanılarak vidalı teflon kalıplara gömüldü. Akrilik rezin bloklar kalıptan çıkarıldı ve kesme cihazı yardımıyla iki eşit parçaya ayrıldı. Parçaların sadece bir yarısında apikalden $2 \mathrm{~mm}$ uzaklıkta yapay standart oluk ( $4 \mathrm{~mm} \times 0.2 \mathrm{~mm} \times 0.5 \mathrm{~mm}$ ) hazırlandı ve içi dentin debrizi ile dolduruldu. Akrilik rezin bloklar tekrar teflon kalıp içerisine yerleștirildi ve kalıp sıkıştırıldı. Debriz uzaklaştırılmasında dört farklı irrigasyon aktivasyon tekniği kullanıldı: Manuel Dinamik İrrigasyon (MDi), Sonik İrrigasyon (Si), Apikal Negatif Basınçlı İrrigasyon (ANBi) ve Pasif Ultrasonik İrrigasyon (PUi). Kontrol grubunda Konvansiyonel Şırınga İrrigasyonu (Ki) uygulandı. Standardizasyonun sağlanması için her örnek temizlenip tekrar kullanıldı $(n=20)$. İrrigasyon öncesi ve sonrası olukların görüntüleri x30 büyütmede operasyon mikroskopu yardımıyla alındı; oluklarda kalan debriz miktarı skorlama yapılarak değerlendirildi. Elde edilen bilgiler Kruskall-Wallis ve MannWhitney $U$ testleri ile analiz edildi $(\alpha=0.05)$.

BULGULAR: Çalışma grupları arasında istatistiksel olarak anlamlı farklııklar gözlendi $(p<0.05)$. Dentin debrizini en etkili uzaklaştıran grup PUi $(0.85 \pm 0.41)$ bulunurken, en az uzaklaştıran grup Ki $(2.30 \pm 1.03)$ olarak bulundu $(p<0.05)$. Ki ve Si, MDi ve PUi, MDi ve ANBi ve Si ve ANBi arasında istatistiksel olarak anlamlı fark yoktu $(p>0.05)$.

Sonuç: Basit ve ucuz bir teknik olan MDi, düşük debriz skorları elde edilen PUi ile benzer sonuçlar gösterdi.

AnahtAR Kelimeler: Endodonti; kök kanal tedavisi; sodium hipoklorit

Makale gönderiliş tarihi: 18 Nisan 2016; Yayına kabul tarihi: 28 Eylül 2016 *iletissim: Dr. Mügem Asıı Ekici, Gazi Üniversitesi, Diș Hekimliği Fakültesi, Endodonti Anabilim Dall, 8. Cadde, 06510, Emek, Ankara, Türkiye;

E-posta: muugeem@hotmail.com
KaYNAK GöStermeK İçiN: Ekici MA, Helvacıoğlu Kıvanç B, Ekici A, Uzun Ö. Farklı endodontik irrigasyon aktivasyon teknikleri kullanılarak yapay oluklardan debriz uzaklaştırılması: ex vivo. Acta Odontol Turc 2017;34(1):14-8 ЕрітӧR: Güven Kayaoğlu, Gazi Üniversitesi, Ankara, Türkiye

YAYıN HAKKI: @ 2017 Ekici ve ark. Bu eserin yayın hakkı Creative Commons Attribution License ile ruhsatlandırılmıştır. Sınırsız kullanım, dağıtım ve her türlü ortamda çoğaltım, yazarlar ve kaynağın belirtilmesi kaydıyla serbesttir.

[Abstract in English is at the end of the manuscript]

\section{Giriş}

Kök kanal tedavisinin en önemli amaçlarından birisi, kök kanal sisteminden mikroorganizmaları uzaklaştırmak ve rekontaminasyonun önüne geçmektir. ${ }^{1}$ Kök kanal sisteminin genelde görülen karmaşık anatomisi, dezenfeksiyonun kusursuz olmasını imkansız kılmaktadır. ${ }^{2}$ Farklı irrigasyon tekniklerinin gelişimi, kök kanal tedavisinde özellikle apikal alanda daha etkili temizliğin sağlanması açısından önemlidir. ${ }^{3}$

Konvansiyonel Şırınga İrrigasyonu'nun (KI) kullanımı halen geniş ölçüde geçerliliğini sürdürse de, ${ }^{4}$ kök kanal düzensizliklerinden debrizi tamamen uzaklaştırmada yetersizdir. ${ }^{5}$ Bu nedenle yıkama solüsyonlarının yıkayıcı, temizleyici etkisini artırmaya yönelik çeşitli teknik ve cihazların geliştirilmesine devam edilmektedir.

Manuel Dinamik İrrigasyon (MDi), kök kanal duvarlarını temizlemek için kullanılan uygun maliyetli mekanik teknik olarak tarif edilmektedir. MDi yöntemi guta-perka gibi inert bir materyalin kanal içinde solüsyon varken apikale doğru aşağı-yukarı hareket ettirilmesiyle uygulanan bir tekniktir. Şekillendirilmiş kanallarda, kanala iyi uyumlu ana konun hareketinin hidrodinamik etki sağlayabileceği ve irrigasyon solüsyonunun yer değişimini kayda değer biçimde artırdığı gösterilmiş̧tir. ${ }^{6}$

Pasif Ultrasonik İrrigasyon (PUi), kanal duvarlarına herhangi bir temas olmadan kök kanalları içerisindeki yıkama solüsyonunun aktivasyonunu sağlamak için ultrasonik olarak aktive edilmiş paslanmaz çelik eğelerin kullanıldığı aktivasyon yöntemidir. ${ }^{7}$ Bu yöntem, irrigasyon solüsyonunun kanal içerisindeki hareketini artırmakta ve debrizin koronal olarak yer değiştirmesini sağlamaktadır. 
PUi, Ki ile karşılaştıııldığında, daha çok dentin debrizi, smear tabakası ve biyofilmi uzaklaştırabilmektedir. ${ }^{8}$

Sonik İrrigasyon Sistemi (Si) (Vibringe; Vibringe Co., Amsterdam, Hollanda) irrigasyon solüsyonunun kök kanallarına gönderilmesi ile sonik aktivasyonun eş zamanlı yapımını kombine eden irrigasyon aktivasyon cihazıdır. Sistem özel olarak dizayn edilmiş kullanat şırınga ve bu şırıngaya tam olarak sığan kablosuz el ünitesinden oluşmaktadır. Bununla birlikte şırınga her türlü irrigasyon iğnesiyle kullanılabilmektedir. Standart şırınga yoluyla irrigasyon solüsyonu kök kanalları içine titreşimli şekilde gönderilebilmektedir. ${ }^{9}$ Vibringe sonik akış teknolojisi ile beraber akustik akımı kullanmaktadır. ${ }^{7}$

Apikal Negatif Basınçlı İrrigasyon Aktivasyon Sistemi (ANBi) (EndoVac; Discus Dental, Culver City, $C A, A B D)$, irrigasyon solüsyonunu apikal sonlanmaya kadar dağıtıp buradaki debrizi geri çekmektedir. ${ }^{10} \mathrm{Ki}$ ile karşılaştırıldığında, yüksek miktardaki irrigasyon solüsyonunun akışı kök kanal sisteminin daha iyi temizlenmesini sağlamaktadır. Makrokanülün apikal 1/3'ün ortasına ve daha sonra mikrokanülün çalışma boyuna kadar yerleştirilmesi, irrigasyon solüsyonunun yeterliakışı ile debriz ve smear tabakasının kaldırılmasını sağlamaktadır. ${ }^{11}$

Debriz uzaklaştırma etkinliğini değerlendirme için kullanmak üzere Lee ve ark. ${ }^{12}$ bir model oluşturmuşlardır ve yapılan birçok çalışmaya örnek teşkil etmiştir. ${ }^{33-16} \mathrm{Bu}$ model prepare edilemeyen yapay düzensizlikleri ve genişlikleri taklit edebilmektedir. ${ }^{12}$

$\mathrm{Bu}$ çalışmanın amacı, farklı irrigasyon aktivasyon tekniklerinin (MDi, PUi, MDi ve ANBi) çekilmiş dişlerin kök kanal sisteminde oluşturulan yapay oluklarda debriz uzaklaştırma etkinliklerinin karşılaştırılmasıdır.

\section{Gereç Ve Yöntem}

Bu çalışmaya başlamadan önce Ankara Üniversitesi Diş Hekimliği Fakültesi Etik Kurulu'nun onayı alındı (Referans No: 36290600\57).

\section{Örneklerin hazırlanması}

Çalışma için yeni çekilmiş yirmi adet düz köke sahip tek kanallı üst çene keser dişi temin edildi ve deney sürecine kadar \%1 timol solüsyonunda saklandı. Dişlerin apeksi kapanmış, tek ve düz bir kök kanalına sahip olması ve köklerde rezorpsiyon, çatlak ve kırık olmadığının doğrulaması için radyografi alındı. Tüm dişlerdeki kök boylarının 14 mm olabilmesi için, kronlar su soğutması altında elmas diskler yardımıyla uzaklaştırıldı. Çalışma boyu, bir 10 nolu K-tipi eğe ile, eğe ucu apikal foramende görünebilir hale geldikten hemen sonra gerçek kök boyundan $1 \mathrm{~mm}$ kısa olacak şekilde ayarlandı. Kök kanalları ProTaper (Dentsply Maillefer, Ballaigues, İsviçre) döner alet sistemi ile üretici firma talimatlarına göre şekillendirildi. Tüm örnekler ana apikal eğe olarak belirlenen ProTaper F3'e (\#30.09) kadar genişletildi. Her alet değişiminden sonra kanallar 30-G irrigasyon iğnesi (Navi Tip; Ultradent, South Jordan, UT, ABD) yardımıyla \%2 sodyum hipoklorit ( $\mathrm{NaOCl} ; 2 \mathrm{~mL}$ ) ile yıkandı. Örnekler akrilik rezin (Imicryl, Konya, Türkiye) kullanılarak vidalı teflon kalıba (15 mm x 15 mm x 20 mm) gömüldü. Akrilik rezin sertleştikten sonra teflon kalıp açıldı ve dişlerin olduğu bloklar çıkarıldı. Blokları ortadan ikiye ayırabilmek için blokların dik aksları boyunca düşük devirde çalışan kesme cihazı (Mecatome, T 201 A, Presi, Grenoble, Fransa) ile çentikler açıldı. Daha sonra bloklar keski yardımıyla ikiye ayrıldı, böylece kökler uzun aksları boyunca iki eşit parçaya ayrıldı (Resim 1). Parçaların sadece bir yarısında çalışma boyundan $2 \mathrm{~mm}$ uzaklıkta ultrasonik retrotip (NSK Varios 750, Nakanishi Inc., Tochigi, Japonya) yardımıyla yapay oluklar (4 $\mathrm{mm} \mathrm{x}$ $0.2 \mathrm{~mm} \times 0.5 \mathrm{~mm}$ ) hazırlandı. Bu deney düzeneği daha önce yapılmış bir çalışmadan örnek alındı. ${ }^{12}$ Örnek dişlerin uzaklaştırılan kron kısımlarından çelik round frez ile dentin talaşı elde edildi. Dentin talaşı \%2 $\mathrm{NaOCl}$ ile karıştırılıp çamurumsu debriz elde edildi. Daha sonra oluklar kağıt konlar yardımıyla çamurumsu dentin debrizi ile dolduruldu. Hemen ardından akrilik bloklar içindeki dişlerin iki eş parçası bir araya getirildi, teflon kalıp içerisine yerleştirildi ve teflon kalıp olabildiğince sıkıştırıldı.

\section{İrrigasyon işlemi}

KI grubu (Kontrol); 30-G irrigasyon iğnesiyle (Ultradent) $10 \mathrm{~mL}, \% 2 \mathrm{NaOCl}$ kullanılarak 2 dakika boyunca aşağıyukarı hareketlerle irrigasyon tamamlandı.

MDi grubu; 30-G irrigasyon iğnesiyle (Ultradent) 5 $\mathrm{mL}, \% 2 \mathrm{NaOCl}$ irrigasyonu sonrası F3 guta-perka konu irrigasyon aktivasyonu için yaklaşık 1 dakika boyunca 100 kez aşağı-yukarı hareket ettirildi ve daha sonra tekrar $5 \mathrm{~mL}$, \%2 NaOCl ile yıkandı.

PUi grubu; 30-G irrigasyon iğnesiyle (Ultradent) 5 $\mathrm{mL}, \% 2 \mathrm{NaOCl}$ irrigasyonu sonrası ultrasonik cihaza (NSK Varios; güç ayarı: 4) ultrasonik endodontik uç takılıp 20 sn aktive edildi, ardından $5 \mathrm{~mL}, \% 2 \mathrm{NaOCl}$ irrigasyonu tekrarlandı.

Si grubu; 30-G irrigasyon iğnesi (Ultradent) ile 10 $\mathrm{mL}, \% 2 \mathrm{NaOCl}$ solüsyonu kanallara verilirken, aynı zamanda sonik irrigasyon yapan Vibringe (Vibringe Co.) irrigasyon cihazı ile 2 dakika boyunca yıkama yapıldı.

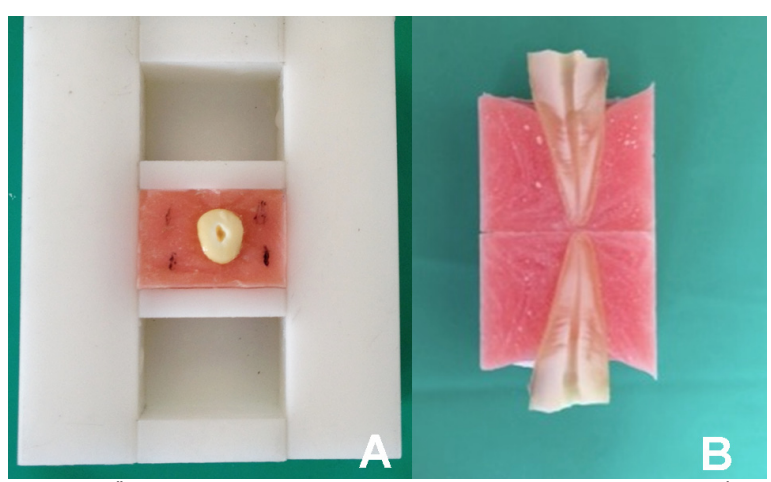

Resim 1. Örneklerin hazırlanması; A: Teflon kalıp içerisindeki örnek, B: ikiye ayrılmış örnek 
Tablo 1. Deney gruplarına göre irrigasyon işlemleri

\begin{tabular}{|c|c|}
\hline Grup & İrrigasyon işlemi \\
\hline Ki & 30-G irrigasyon iğnesi + \%2'lik $10 \mathrm{~mL} \mathrm{NaOCl}$ \\
\hline MDi & $\begin{array}{l}\text { 30-G irrigasyon iğnesi + \%2'lik } 5 \mathrm{~mL} \mathrm{NaOCl}+\mathrm{F} 3 \text { guta- } \\
\text { perka ile aktivasyon }+30-\mathrm{G} \text { irrigasyon iğnesi }+\% 2 \text { 'lik } 5 \mathrm{~mL} \\
\mathrm{NaOCl}\end{array}$ \\
\hline PUi & $\begin{array}{l}\text { 30-G irrigasyon iğnesi + \%2'lik } 5 \mathrm{~mL} \mathrm{NaOCl}+\text { ultrasonik } \\
\text { uç ile aktivasyon + 30-G irrigasyon iğnesi + \%2'lik } 5 \mathrm{~mL} \\
\mathrm{NaOCl}\end{array}$ \\
\hline si & $\begin{array}{l}30-\mathrm{G} \text { irrigasyon iğnesi }+\% 2 \text { 'lik } 10 \mathrm{~mL} \mathrm{NaOCl}+\text { Vibringe ile } \\
\text { aktivasyon }\end{array}$ \\
\hline ANBi & $\begin{array}{l}\text { (30-G irrigasyon iğnesi }+3 \mathrm{~mL} \% 2^{\prime} \text { lik NaOCl }+ \text { EndoVac } \\
\text { mikrokanülü ile aktivasyon) x } 3+1 \mathrm{ml} \% 2^{\prime} l i k \mathrm{NaOCl}\end{array}$ \\
\hline
\end{tabular}

Ki: Konvansiyonel Irrigasyon, MDi: manuel Dinamik irrigasyon, PUi: Pasif Ultrasonik Irrigasyon, Si: Sonik Irrigasyon, ANBi: Apikal Negatif Basınçlı irrigasyon

ANBI grubu; 30-G irrigasyon iğnesi (Ultradent) ile $3 \mathrm{~mL}, \% 2 \mathrm{NaOCl}$ irrigasyonunun ardından EndoVac (Discus Dental) mikrokanülü yardımıyla çalışma boyunda: $6 \mathrm{sn}$, çalışma boyundan $2 \mathrm{~mm}$ kısa: $6 \mathrm{sn}$ olacak şekilde korono-apikal yönde hareket ettirilerek 30 sn boyunca aktivasyon yapıldı ve bu döngü 3 kez tekrarlandı. Ardından kök kanalları $1 \mathrm{~mL}, \% 2 \mathrm{NaOCl}$ ile tekrar yıkanarak süreç tamamlandı.

İrrigasyon tüm deneysel gruplarda çalışma boyundan $1 \mathrm{~mm}$ kısa ve her örnek için toplam $10 \mathrm{~mL}$ olacak şekilde $\% 2 \mathrm{NaOCl}$ ile yapıldı (Tablo 1). Çalışma sırasında standardizasyonu sağlamak amacıyla uygulamalar arasında her örnek tamamen temizlendikten sonra 5 deneysel grup için tekrar kullanıldı.

\section{Örneklerin değerlendirilmesi}

Kök kanallarında oluşturulan yapay kanal düzensizliklerindeki kalan debriz miktarını değerlendirmek amacıyla, gruplardaki irrigasyon ve aktivasyon işlemleri sonrası dişlerin gömüldüğü akrilik rezin bloklar açıldı. İrrigasyon öncesi ve sonrası kök yarılarından operasyon mikroskopu (OPMI Pico, Carl Zeiss, Almanya) yardımıyla x30 büyütme altında dijital fotoğraflar alındı. Oluklarda kalan debriz miktarının ölçümü, hangi aktivasyon tekniğinin uygulandığına dair bilgisi olmayan 2 araştırmacı tarafından skorlandı (A.E., M.A.E.). Skorlama 0: oluk tamamen temiz, 1: oluğun

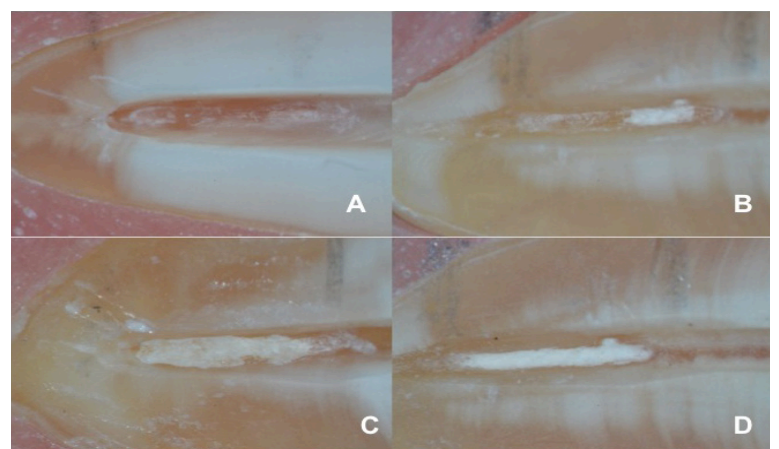

Resim 2. Yapay oluşturulan oluklarda kalan dentin debrizi miktarı; (A) Skor 0: Oluk boş, (B) Skor 1: Oluğun yarısından daha azı debriz ile dolu, (C) Skor 2: Oluğun yarısından fazlası debriz ile dolu, (D) Skor 3: Oluk tamamen debriz ile dolu yarısından fazlası temiz, 2: oluğun yarısından fazlası debrizle dolu, 3: oluk tamamen debrizle dolu olmak üzere sayısal değerler üzerinden yapıldı (Resim 2). ${ }^{13}$ Elde edilen sonuçlar Kruskall-Wallis ve Mann Whitney $U$ testleriyle analiz edildi ( $\alpha=0.05)$.

\section{Bulgular}

Araştırmacılar skorlama sonuçlarında 4 örnekte farklı karar verdi; anlaşmazlık tartışma yoluyla giderildi. İrrigasyon öncesi debrizle dolu olukların skorları ' 3 ' olarak kaydedildi. Çalışmanın sonuçları Tablo 2'de gösterildi. Çalışma grupları arasında istatistiksel olarak anlamlı farklılıklar bulundu ( $\mathrm{p}<0.05$; Kruskal-Wallis).

Tüm gruplar içerisinde, debrizin olukta en az kaldığı grup PUi idi. PUi grubu diğer gruplarla karşılaştırıldığında aralarında istatistiksel olarak anlamlı farklılık bulundu (MDí grubu hariç, $\mathrm{p}<0.05$ ). PUi, diğer deney gruplarına oranla daha fazla debriz uzaklaştırdı.

Tüm gruplariçerisinde, debrizin olukta en fazla kaldığı grup Ki idi. Ki grubu diğer gruplarla karşılaştırıldığında aralarında istatistiksel olarak anlamlı farklılık bulundu (Si grubu hariç, $\mathrm{p}<0.05$ ). KI grubu, diğer tüm gruplardan daha az miktarda dentin debrizi uzaklaştırdı.

MDi ile ANBI arasında ve si ile ANBí arasında istatistiksel olarak anlamlı bir fark bulunmadı ( $p>0.05)$.

\section{TARTIŞMA}

Çalışmanın deney dizaynını Lee ve ark. ${ }^{12}$ tarif etmiş ve birçok çalışmaya da örnek olmuştur. ${ }^{13-16}$ Çalışmada kullanılan oluk modelinin avantajı, olukların standardize edilebilen büyüklüğü ve konumudur. Modelin en büyük dezavantajı ise, yapay olukların kompleks kök kanal anatomisini tam olarak yansıtamıyor oluşudur. Klinik şartlarda istmuslardan veya oval çıkıntılardan debriz uzaklaştırıması, yapay oluklardan debriz uzaklaştırılmasından daha zordur. Yapay oluklar irrigasyon cihaz ve tekniklerinin başarı şansını artırabilmektedir. ${ }^{16}$ Çalışmada deney grupları arasında benzer koşulların sağlanabilmesi için $10 \mathrm{~mL}$ irrigasyon solüsyonu kullanıldı ve tüm irrigasyon sistemlerinde

Tablo 2. Deney grupları için skor ortalamaları

\begin{tabular}{llll}
\hline Grup & $\mathbf{n}$ & Ortalama \pm SD & Karşılaştırma \\
\hline Ki & 20 & $2.30 \pm 1.03$ & $\mathrm{a}$ \\
MDi & 20 & $1.10 \pm 064$ & $\mathrm{bc}$ \\
PUi & 20 & $0.85 \pm 0.41$ & $\mathrm{~b}$ \\
Si & 20 & $1.75 \pm 1.11$ & $\mathrm{ad}$ \\
ANBi & 20 & $1.30 \pm 0.47$ & $\mathrm{~cd}$ \\
\hline
\end{tabular}

Ki: Konvansiyonel Irrigasyon, MDi: manuel Dinamik Irrigasyon, PUi: Pasif Ultrasonik Irrigasyon, Si: Sonik Irrigasyon, ANBi: Apikal Negatif Basınçlı İrigasyon, n: örnek sayısı, SD: standart sapma. Karşılaştırma sütununda, farklı harfler gruplar arasında istatistiksel olarak anlamlı fark olduğunu $(p<0.05)$, aynı harfler gruplar arasında istatistiksel olarak anlamlı fark olmadığını göstermektedir ( $p>0.05)$. 
kanüller veya cihazlar yapay oluklara aynı mesafede konumlandırıldı. Standardizasyon için her örnek tamamen temizlendikten sonra deney grupları için tekrar kullanıldı.

Geleneksel olarak irrigasyon solüsyonları kök kanal boşluğuna değişik çap ve dizaynlara sahip şırınga ve iğneler yardımıyla dağıtılmaktadır. Bu klasik yaklaşım kanallar arasındaki anastomozlar ve kanalların apikal kısımları gibi bazı çevresel sayılabilecek alanların irrigasyonunu yetersiz kılmaktadır. ${ }^{11}$ Çalışmada çıkan sonuçlardan bir tanesi, tüm irrigasyon teknik ve cihazlarının debriz uzaklaştırmada Ki'den başarılı bulunmasıdır.

Çalışmada PUI grubu diğer gruplara nazaran dentin debrizini daha etkili bir biçimde uzaklaştırdı. Dentin debrizinin PUi grubunda daha etkili şekilde uzaklaştırılması, yüksek ultrason frekansına (30 kHz) bağlı olabilir. Sonik frekansa $(150 \mathrm{~Hz})$ göre ultrasonik frekansın yüksek oluşu, kök kanal uzantılarına irrigasyon solüsyonunun ulaşımını kolaylaştırmakta ve irrigasyon solüsyonunun akış hacmini ve temizleme özelliklerini artırmaktadır. Çalışma sonuçları, PUI'nin, Si, $\left.{ }^{16,17} \mathrm{ANBi}\right|^{8,18}$ ve Ki'ye ${ }^{12,16,19-21}$ kıyasla dentin debrizini daha iyi uzaklaştırdığını savunan diğer çalışmaların sonuçlarını desteklemektedir. Bu çalışma sonuçlarının tersine Mancini ve ark. ${ }^{22}$ yaptıkları çalışmada, apikal negatif basınçlı irrigasyonun ultrasonik irrigasyona göre smear tabakasını ve dentin debrizini daha iyi uzaklaştırdığı sonucuna varmışlardır. Mancini ve ark. ${ }^{22}$ çalışmalarında son yıkamada \%17 EDTA ve distile su kullanmışlar, bu da toplam irrigasyon süresini ve kullanılan irrigasyon solüsyonunun hacmini artırmıştır. $\mathrm{Bu}$ çalışmadaki irrigasyon protokolü, yaptığımız çalışmanın irrigasyon protokolünden farklıdır.

MDi'nin etkinliği, kanal preparasyonu miktarı ve konikliğine bağlı olarak seçilen guta-perka konuna bağlı olabilir. ${ }^{8}$ Konikleştirilmiş kanal preparasyonu, kon aşağı hareket ettiğinde irrigasyon solüsyonunun yukarı, kon yukarı hareket ettiğinde solüsyonun aşağı doğru hareketiyle hidrodinamik etki oluşturur. ${ }^{23}$ Bu çalışmada MDI'nin debriz uzaklaştırma etkinliğinin PUi ve ANBi grubuyla eşdeğer olduğu bulundu. Bu bulgu Susin ve arkadaşlarının ${ }^{24}$ farklı kanal seviyelerinde MDi ve ANBI'nin debriz uzaklaştırmada benzer etkinliğe sahip olduğunu gösterdiği çalışmanın bulguları ile benzerdir. Bu çalışmadan farklı olarak Parente ve ark. ${ }^{25}$ açık ve kapalı kanal sistemlerinde ANBI'nin MDI'ye göre üstün olduğu sonucuna varmışlardır. Araştırmacılar yaptıkları çalışmada \%5.25 NaOCl ve \%17 EDTA olmak üzere toplamda $15 \mathrm{~mL}$ irrigasyon solüsyonu kullanmışlardır. Yaptığımız çalışmada daha önce yapılan bazı çalışmaların ${ }^{3,8}$ sonuçlarına uygun olarak MDI'nin Kl'den daha etkili olduğu bulundu. Bu çalışmanın sonuçlarının aksine Caron ve ark. $^{3}$ farklı bir irrigasyon solüsyonu kullandıkları çalışmalarında MDi ve Si etkinliği açısından istatistiksel olarak anlamlı farklılık bulamamışlardır.

Bizimbulgularımıza paralelolarakbazı araştırmacılar
EndoVAC sisteminin debriz uzaklaştırmada KI'ye göre daha etkili olduğunu göstermişlerdir. 8,18,26,27 $^{2}$ EndoVAC sistemi apikalde negatif basınç yaklaşımını kullandığından, debriz uzaklaştırmada etkili olabileceği düşünülmektedir. ${ }^{25} \mathrm{KI}$ ile kıyaslandığında aynı zaman aralığında, EndoVAC sisteminin önemli miktarda fazla irrigasyon solüsyonunu apikale dağıtabildiği gösterilmiştir. ${ }^{11}$ Gregoria ve ark. ${ }^{28}$ prepare edilemeyen alanlarda ANBl'nin PUi ile karşılaştırıldığında sınırlı etkiye sahip olduğunu göstermişlerdir. Onlar bu sonucu Pashley ve ark. ${ }^{29}$ tarafından tarif edilen ozmotik çekim etkisine bağlamışlardır. Bu parametreler ışığında PUi'nin lateral kanallara penetrasyonu önemli derecede artmıştır. Bu da çalışmamızın sonuçlarıyla uyumludur.

Vibringe irrigasyon solüsyonunun ajitasyonu için sonik aktivasyon kullanmaktadır. Bu çalışmada Vibringe sistemi Kl'ye göre debriz uzaklaştırmada daha etkili bulundu ancak istatistiksel olarak anlamlı fark bulunmadı. Johnson ve ark. ${ }^{30}$ Vibringe ve yandan perfore iğne ucu ile yaptıkları çalışmalarında temizleme etkinliği açısından yöntemler arasında anlamlı fark olmadığı sonucuna varmışlardır. Diğer taraftan Rödig ve ark. ${ }^{16}$ Vibringe sisteminin debriz uzaklaştırmada Kl'ye göre daha üstün olduğunu göstermişlerdir. Yayınlanan makalelerin yetersizliğinden dolayı Vibringe sisteminin debriz uzaklaştırma etkinliğini değerlendiren daha ileri çalışmalara gereksinim duyulmaktadır.

\section{SonUÇ}

$\mathrm{Bu}$ in vitro çalışmanın sonuçlarına göre, test edilen deney gruplarında irrigasyon aktivasyon sistemlerinin hiçbiri yapay düzensizliklerden dentin debrizini tamamen uzaklaştıramadı. Kolay ve uygun maliyetli MDi, deney grupları arasında en etkin şekilde dentin debrizini uzaklaştıran PUi'ye benzer etkinliğine sahiptir.

\section{TEŞEKKÜR VE ANMA}

Bu çalışma 01-04 Haziran 2013 tarihinde Yunan adaları ve Atina'da düzenlenen Türk Endodonti Derneği 5. Bilimsel Sempozyumunda sözlü olarak sunulmuştur.

Çıkar çatışması: Yazarlar bu çalışmayla ilgili herhangi bir çıkar çatışmalarının bulunmadığını bildirmişlerdir.

\section{KAYNAKLAR}

1. Mamootil K, Messer $\mathrm{HH}$. Penetration of dentinal tubules by endodontic sealer cements in extracted teeth and in vivo. Int Endod J 2007; 40:873-81

2. Peters LB, Wesselink PR. Periapical healing of endodontically treated teeth in one and two visits obturated in the presence or absence of detectable microorganisms. Int Endod J 2002;35:660-7.

3. Caron G, Nham K, Bronnec F, Machtou P. Effectiveness of different final irrigant activation protocols on smear layer removal in curved canals. J Endod 2010;36:1361-6.

4. Peters OA. Current challenges and concepts in the preparation of root canal systems: a review. J Endod 2004;30:559-67.

5. Wu MK, Wesselink PR. A primary observation on the preparation and obturation of oval canals. Int Endod J 2001;34:137-41.

6. McGill S, Gulabivala K, Mordan N, Ng YL. The efficacy of dynamic 
irrigation using a commercially available system (RinsEndo) determined by removal of a collagen 'biomolecular film' from an ex vivo model. Int Endod J 2008;41:602-8.

7. Ahmad M, Roy RA, Kamarudin AG. Observations of acoustic streaming fields around an oscillating ultrasonic file. Endod Dent Traumatol 1992;8:189-94.

8. Saber Sel-D, Hashem AA. Efficacy of different final irrigation activation techniques on smear layer removal. J Endod 2011;37:1272-5.

9. Bolles JA, He J, Svoboda KK, Schneiderman E, Glickman GN Comparison of Vibringe, EndoActivator, and needle irrigation on sealer penetration in extracted human teeth. J Endod 2013;39:708-11.

10. Schoeffel GJ. The EndoVac method of endodontic irrigation: part 2-efficacy. Dent Today 2008;27:82-7.

11. Nielsen BA, Craig Baumgartner J. Comparison of the EndoVac system to needle irrigation of root canals. J Endod 2007;33:611-5

12. Lee SJ, Wu MK, Wesselink PR. The effectiveness of syringe irrigation and ultrasonics to remove debris from simulated irregularities within prepared root canal walls. Int Endod J 2004;37:672-8.

13. van der Sluis $L W$, Wu MK, Wesselink PR. The evaluation of removal of calcium hydroxide paste from an artificial standardized groove in the apical root canal using different irrigation methodologies. Int Endod J 2007;40:52-7

14. van der Sluis LW, Wu MK, Wesselink PR. The efficacy of ultrasonic irrigation to remove artificially placed dentine debris from human root canals prepared using instruments of varying taper. Int Endod $\mathrm{J}$ 2005;38:764-8

15. van der Sluis LW, Wu MK, Wesselink PR. A comparison between a smooth wire and a K-file in removing artificially placed dentine debris from root canals in resin blocks during ultrasonic irrigation. Int Endod J 2005;38:593-6.

16. Rödig $T$, Bozkurt $M$, Konietschke $F$, Hülsmann M. Comparison of the Vibringe system with syringe and passive ultrasonic irrigation in removing debris from simulated root canal irregularities. J Endod 2010;36:1410-13

17. Jiang LM, Verhaagen B, Versluis M, van der Sluis LW. Evaluation of a sonic device designed to activate irrigant in the root canal. $\mathrm{J}$ Endod 2010;36:143-6

18. Ribeiro EM, Silva-Sousa YT, Souza Gabriel AE, Sousa-Neto MD, Lorencetti KT, Silva SR. Debris and smear removal in flattened root canals after use of different irrigant agitation protocols. Microsc Res Tech 2012;75:781-90.

19. Passarinho-Neto JG, Marchesan MA, Ferreira RB, Silva RG, SilvaSousa YT, Sousa-Neto MD. In vitro evaluation of endodontic debris removal as obtained by rotary instrumentation coupled with ultrasonic irrigation. Aust Endod J 2006;32:123-8.

20. Cheung GS, Stock CJ. In vitro cleaning ability of root canal irrigants with and without endosonics. Int Endod J 1993:26:334-43.

21. Rödig $T$, Sedghi $M$, Konietschke $F$, Lange $K$, Zieboiz D, Hülsmann M. Efficacy of syringe irrigation, RinsEndo and passive ultrasonic irrigation in removing debris from irregularities in root canals with different apical sizes. Int Endod J 2010;43:581-9.

22. Mancini M, Cerroni L, Iorio L, Armellin E, Conte G, Cianconi L. Smear layer removal and canal cleanliness using different irrigation systems (EndoActivator, EndoVAC and passive ultrasonic irrigation): field emission scanning electron microscopic evaluation in an in vitro study. J Endod 2013;39:1456-60.

23. Bronnec F, Bouillaguet $S$, Machtou P. Ex vivo assessment of irrigant penetration and renewal during the final irrigation regimen. Int Endod J 2010;43: 663-72

24. Susin L, Liu Y, Yoon JC, Parente JM, Loushine RJ, Riccucci D, et al. Canal and isthmus debridement efficacies of two irrigant agitation techniques in a closed system. Int Endod 2010;43:1077-90.

25. Parente JM, Loushine RJ, Susin L, Gu L, Looney SW, Weller RN, et al. Root canal debridement using manual dynamic agitation or the EndoVac for final irrigation in a closed system and an open system. Int Endod J 2010;43:1001-12.
26. Gade VJ, Sedani SK, Lokade JS, Belsare LD, Gade JR. Comparative evaluation of debris removal from root canal wall by using EndoVAC and conventional needle irrigaton: An in vitro study. Contemp Clin Dent 2013;4:432-6.

27. Saini M, Kumari M, Taneja S. Comparative evaluation of the efficacy of three different irrigation devices in removal of debris from root canal at different levels: An in vitro study. J Conserv Dent 2013;16:509-13.

28. de Gregorio C, Estevez R, Cisneros R, Paranjpe A, Cohenca N. Efficacy of different irrigation and activation systems on the penetration of sodium hypochlorite into simulated lateral canals and up to working lenght: an in vitro study. J Endod 2010;36:1216-21.

29. Pashley EL, Birdsong NL, Bowman K, Pashley DH. Cytotoxic effects of $\mathrm{NaOCl}$ on vital tissue. J Endod 1985;11:525-8.

30. Johnson M, Sidow SJ, Looney SW, Lindsey K, Niu LN, Tay FR. Canal and isthmus debridement efficacy using a sonic irrigation technique in a closed-canal system. J Endod 2012;38:1265-8.

\section{Debris removal from artificial grooves using different endodontic irrigation activation techniques: ex vivo}

\begin{abstract}
OBJEctive: The aim of this study was to compare the debris removal efficiency of different irrigation activation techniques from artificially formed endodontic grooves.
\end{abstract}

Materials AND Method: Crowns of twenty maxillary incisor teeth were removed and the root canals were prepared. Specimens were embedded in acrylic resin and placed into teflon molds. Acrylic resin blocks were removed from the molds and split longitudinally into equal two halves. A standardized artificial groove $(4 \mathrm{~mm} \times 0.2 \mathrm{~mm}$ $x \mathbf{0 . 5} \mathrm{mm}$ ) was prepared at $2 \mathrm{~mm}$ distance from the apex and filled with dentinal debris. Acrylic resin blocks were placed into the teflon mold again and compressed. Four different irrigation activation techniques; Manual Dynamic Irrigation (MDI), Passive Ultrasonic Irrigation (PUI), Sonic Irrigation (SI) and Apical Negative Pressure Irrigation (ANPI) were used for debris removal. Conventional Irrigation $(\mathrm{Cl})$ was applied as control. For standardization, each specimen was cleaned and reused $(n=20)$. Before and after irrigation, images of the grooves were taken by using an operating microscope at $\times 30$ magnification. Amount of remaining debris was evaluated by using a scoring system. Data were analyzed by using KruskallWallis and Mann-Whitney $U$ tests $(\alpha=0.05)$.

REsults: There were statistically significant differences between the experimental groups $(p<0.05)$. PUI $(0.85 \pm 0.41)$ was found to be the most effective technique; whereas $\mathrm{Cl}$ $(2.30 \pm 1.03)$ was found to be the least effective technique for debris removal $(p<0.05)$. There was no statistically significant difference between groups $\mathrm{Cl}$ and $\mathrm{SI}$, MDI and PUI, MDI and ANPI, and SI ve ANPI ( $p>0.05)$.

Conclusion: PUI yielded the lowest debris scores. A simple and low-cost technique, MDI, yielded similar results with PUI.

KEYwORDS: Endodontics; root canal therapy; sodium hypochlorite 